\title{
A Comparison of Analytical Methods for the Content and Purity of Cefradine
}

\author{
Myung Ho Hyun, Euh Duck Jeong, ${ }^{*}$ Min Seob Shin, and Jong Sung Jin ${ }^{+*}$ \\ Department of Chemistry and Chemistry Institute for Functional Materials. Pusan National Lniversity. Pusan 609-735, Korea \\ -High-Technologv Components \& Materials Research Center \& Busan Center, Korea Basic Science Institute (KBSI). \\ Pusan 609-735. Korea. ${ }^{*}$ E-mail: jsimiäkbsire.kr \\ Received Angust 28, 2007
}

\begin{abstract}
Two HPLC methods such as cefadroxil and cefalexin methods were compared in their performance for the quantitative analysis of the content and purity of $\beta$-lactamic antibiotic. cefradine, for six bulk drug samples. Between the two methods. the cefadroxil method prescribed by the European Plarnacopoeia (EP) for the determination of impurities in cefradoxil was superior to the cefalexin method prescribed by the EP and by the United States Phanmacopeia (USP) for the determination of cefalexin impurity in cefradine in terms of the greater stability of the chromatogram baselines and the higher precision, i.e.. the lower \% relative standard deviation (RSD). Based on the comparison of the two HPLC methods, the cefadroxil method was recommended to replace the TLC method. which has been prescribed by the EP as the official method for determination of extraneous impurities in cefradine.
\end{abstract}

Key Words : Cefradine. Cefalexin. Cefadroxil. Impurity

\section{Introduction}

Cefradine is an important cephalosporin antibiotic drug. Cefalexin is a major impurity in cefradine. For the analysis of cefradine and cefalexin, micellar electrokinetic chromatography by the capillary electrophoresis method. ${ }^{1}$ liquid chromatography (LC) on poly (styrene-divinylbenzene), ${ }^{\hat{}}$ a comparative study of two isocratic liquid chromatography methods using a classical colunun $\left(\mathrm{C}_{18}\right)$ and poly(styrenedivinylbenzene) as the stationary phase ${ }^{3}$ and thin-layer cliromatography (TLC) method have been reported.

Cephalosporins are commonly analyzed using LC methods with absorbance detection. ${ }^{5.17}$ Official methods to assess antibiotic identity. strength. quality, and purity of cephalosporins are described in the Code of Federal Regulations (CFR Title 21). the United States Pharmacopoeia (USP) and the European Pharmacopoeja (EP).

In the EP ${ }^{18}$ and USP, ${ }^{19}$ an isocratic HPLC method was developed and validated for determination of cefalexin. the major inpurity in cefradine. However. this method does not allow for characterization of any extraneous impurities. The analytical methods prescribed by the EP and USP for analysis of impurities in cefradine and cefadroxil are summarized in Table 1. As shown in Table 1. a TLC method is prescribed by the EP for determination of extraneous impurity levels in cefradine. The TLC method is simple and does not require special equipment. However. it is rarely used to analyze impurities due to its low sensitivity and low reproducibility compared with HPLC method. ${ }^{\text {ij }}$ HPLC method is the most widely used teclunique for analysis of bulk drugs and their formulations. ${ }^{13.22}$

As shown in Table 2. limitations on the allowable impurity content in cefradine are clearly described by the EP and USP. Even though a rapid and simple HPLC method has been developed to assay antibiotic and impurity levels in bulk drugs, ${ }^{21}$ the official method for determination of extraneous impurities in cefradine is TLC method according to the EP and USP as shown in Table 1.

In this study, as an effort to propose more reliable method than TLC method. the content of cefradine and all impurities will be assayed for six cefradine bulk drugs by using the cefalexin method. the official HPLC method prescribed by the EP for analyzing cefalexin, the major impurity in cefradine. In addition, the content of cefradine and all impurities will be assayed by using the cefadroxil method. the official HPLC method prescribed by the EP for all

Table 1. Methods for the analy sis of impurities in cetradine and cefadroxil prescribed by the EP and USP

\begin{tabular}{|c|c|c|c|c|c|c|}
\hline $\begin{array}{c}\text { Raw } \\
\text { material }\end{array}$ & $\begin{array}{l}\text { Phanmaco- } \\
\text { poeia }\end{array}$ & Impurity & Detector & Mobile phase & Column & Flow rate \\
\hline \multirow{3}{*}{ Cefradine } & \multirow[b]{2}{*}{$\mathrm{EP}$} & Cefalexin & UV $254 \mathrm{~mm}$ & Acetate bufter solution with methanol & $\mathrm{C}_{18}(4.6 \times 250 \mathrm{~mm})$ & $1.0 \mathrm{~mL} / \mathrm{min}$ \\
\hline & & $\begin{array}{l}\text { Any extraneous } \\
\text { inpurity }\end{array}$ & \multicolumn{4}{|c|}{ ILC analytical method } \\
\hline & USP & Cetalexin & UV $254 \mathrm{~mm}$ & Acetate buffer solution with methanol & $C_{18},(4.6 \times 250 \mathrm{~mm})$ & $1.0 \mathrm{~mL} / \mathrm{min}$ \\
\hline \multirow[t]{2}{*}{ Cefadroxil } & $\mathrm{EP}$ & All impurities & UV $220 \mathrm{~mm}$ & Phosphate bufter $(\mathrm{pH}=5.0)$ with methanol & $C_{18},(4.6 \times 100 \mathrm{~mm})$ & $\begin{array}{l}1.5 \mathrm{~mL} / \mathrm{min} 1 \\
\text { (Gradient) }\end{array}$ \\
\hline & USP & All impurities & \multicolumn{4}{|c|}{ ILC analytical method } \\
\hline
\end{tabular}


impurities in cefadroxil. ${ }^{\hat{1}}$ Comparison of the two HPLC methods is expected to provide more reliable method than TLC method for determination of the content of cefradine and its all inpurities.

\section{Experimental}

Chemicals. The standards were USP products. The structures of cefradine. cefalexin and cefadroxil are shown in Figure 1. The Korean Food and Drug Administration (KFDA) donated all of the bulk drugs to the Research Project on the Quality Control of Standard Drugs. Methanol and water. both HPLC grade, were obtained from Merck (Darmstadt. Germany). Glacial acetic acid. sodium acetate and potassium dihydrogen phosphate were purchased from Sigma-Aldrich Chenical. Korea Ltd. (Seoul. Korea). All reagents were analy tical-grade.

Preparation of mobile phases and samples. For HPLC analysis of substances related to cefradine, mobile phases and standard samples were prepared according to the "cefalexin method" described in the EP. For the development of the cefradine impurity test. samples were treated according to the cefadroxil sample preparation method described in the EP. Mobile phases were degassed by ultrasonication. The concentrations of the six bulk drug samples were similar to that of the standard solution.

Each of the six bulk drug samples was injected three times to obtain \% area and \% RSD data. The cefradine inpurity test was completed according to the "cefalexin method" described in the EP within $8 \mathrm{hr}$ and $40 \mathrm{~min}$. producing three clromatograms for each bulk drug. The interval between sample injections was approximately 4 hr and $20 \mathrm{~min}$. The cefradine impurity test performed according to the "cefadroxil method" was completed within $10 \mathrm{lu}$ and $20 \mathrm{~min}$, producing three chromatograms for each bulk drug. The sample injection interval was approximately $5 \mathrm{hr}$ and $10 \mathrm{~min}$.

Equipment. The HPLC system was a Waters (Milford. MA. USA) Alliance 2695 separations module system consisting of a 2996 photo diode detector interfaced with a PC data system. Chromatographic data were manipulated using Empower software from Waters Korea Ltd. (Seoul. Korea). HPLC separations were performed with a $C_{18} 250 \mathrm{~mm} \times 4.6$ $\mathrm{mm}$ (UGL20 $5 \mathrm{~km}$ particle size) column from Shiseido Capcell pak (Tokyo. Japan). The column operating temperature was maintained at $30^{\circ} \mathrm{C}$. Other HPLC conditions are summarized in Table 3. Column length and sample temperature given in the EP were modified slightly in the present study to obtain comparable data.

\section{Results and Discussion}

Chromatographic results for the determination of impurities in cefradine with "cefalexin method". The HPLC conditions were those described for the "cefalexin method" in the EP to improve analysis of the impurities in cefradine over the TLC method. The ratio of the major impurity, cefalexin. and any other impurities in cefradine was checked with the "cefalexin method." The method was quite successful in determining the content of all impurities in cefradine. The method facilitated simultaneous determination of cefradine content, which is not possible with TLC method. (a)

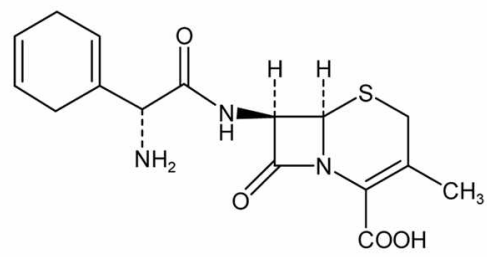

(b)

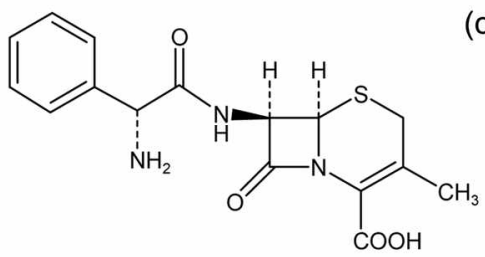

(c)

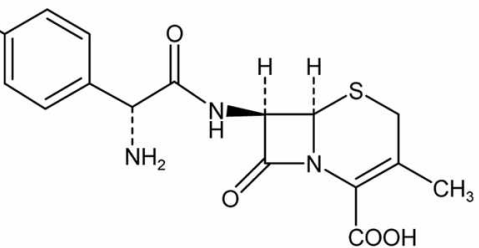

Figure 1. Structures of cetradine (a), cefalexin (b) and cefadroxil (c).

Table 2. Specification of impurities in cefradine prescribed by the EP and USP

\begin{tabular}{cllc}
\hline \multirow{2}{*}{ Raw material } & Impurity & EP & Specification \\
\cline { 3 - 4 } & & Not more than $5.0 \%$ & Not more than $5.0 \%$ \\
\hline \multirow{2}{*}{ Cefradine } & Cefalexin & Not more than $1.0 \%$ & - \\
\hline
\end{tabular}

Table 3. HPLC conditions for the analy sis of cefradine using the "cefalexin" and "cefadroxil" methods

\begin{tabular}{|c|c|c|c|c|}
\hline Method & Raw material & $\begin{array}{l}\text { Detection } \\
\text { wavelength }(\mathrm{nm})\end{array}$ & Mobile phase & flow rate \\
\hline Cetalexin method & Cetradine & 254 & $\begin{array}{l}0.0052 \mathrm{~mol} / \mathrm{L} \text { Sodium acetate solution Methanol } \\
\text { - Acetic acid (800:200:0.12) }\end{array}$ & $\begin{array}{l}1.0 \mathrm{~mL} / \mathrm{min} \\
\text { (Isocratic) }\end{array}$ \\
\hline \multirow[t]{2}{*}{ Cetadroxil method } & Cefradine & 254 & $\begin{array}{l}\text {-Mobile phase A: Potassium dihydrogen } \\
\text { phosphate buffer solution }(\mathrm{pH}=5.0)\end{array}$ & $\begin{array}{l}1.5 \mathrm{~mL} / \mathrm{min} \\
\text { (Gradient condition is }\end{array}$ \\
\hline & Cetadroxil & 220 & -Mobile phase B: Methanol & consent with the EP. ) \\
\hline
\end{tabular}


Table 4. Chromatographic results including retention time and \% area of each peak obtained with "cetalexin method" for six cetradine bulk drug samples $(\mathrm{A} \sim \mathrm{F})$

\begin{tabular}{|c|c|c|c|c|c|c|c|}
\hline $\mathrm{Sa}$ & RT (min) & $\%$ Area $^{a}$ & Componnd & $\mathrm{Sa}$ & RT (min) & $\%$ Area & Compound \\
\hline \multirow{6}{*}{ A } & 3.45 & 0.02 & $\mathrm{UN}^{b}$ & \multirow{6}{*}{ D } & 3.43 & 0.02 & UN \\
\hline & 4.00 & 0.08 & UN & & 3.99 & 0.08 & UN \\
\hline & 10.24 & 2.34 & Cefalexin & & 5.14 & 0.10 & UN \\
\hline & 1503 & 96.63 & Cetradine & & 10.23 & 2.26 & Cefalexin \\
\hline & 23.99 & 0.93 & UN & & 1502 & 96.14 & Cefradine \\
\hline & & & & & 23.99 & 1.41 & UN \\
\hline \multirow{6}{*}{ B } & 3.44 & 0.05 & UN & \multirow{6}{*}{ E } & 3.44 & 0.04 & UN \\
\hline & 401 & 0.10 & UN & & 399 & 0.03 & UN \\
\hline & 5.13 & 0.09 & UN & & 5.13 & 0.06 & UN \\
\hline & 10.24 & 2.14 & Cetalexin & & 10.23 & 2.26 & Cefalexin \\
\hline & 1502 & 96.20 & Cefradine & & 15.02 & 96.61 & Cefradine \\
\hline & 24.03 & 1.41 & UN & & 23.95 & $1 .(12$ & UN \\
\hline \multirow{6}{*}{ C } & 3.45 & 0.11 & UN & \multirow{6}{*}{ F } & 3.44 & 0.03 & UN \\
\hline & 400 & 0.08 & UN & & 4.00 & 0.04 & UN \\
\hline & 10.24 & 3.46 & Cefalexin & & 5.13 & 0.18 & UN \\
\hline & 1503 & 95.65 & Cefradine & & 10.24 & 3.27 & Cetalexin \\
\hline & 24.04 & 0.70 & UN & & 15.01 & 95.47 & Cetradine \\
\hline & & & & & 24.02 & 1.01 & $\mathrm{UN}$ \\
\hline
\end{tabular}

"Average of 0 . Area to 3 times. "Unbinown

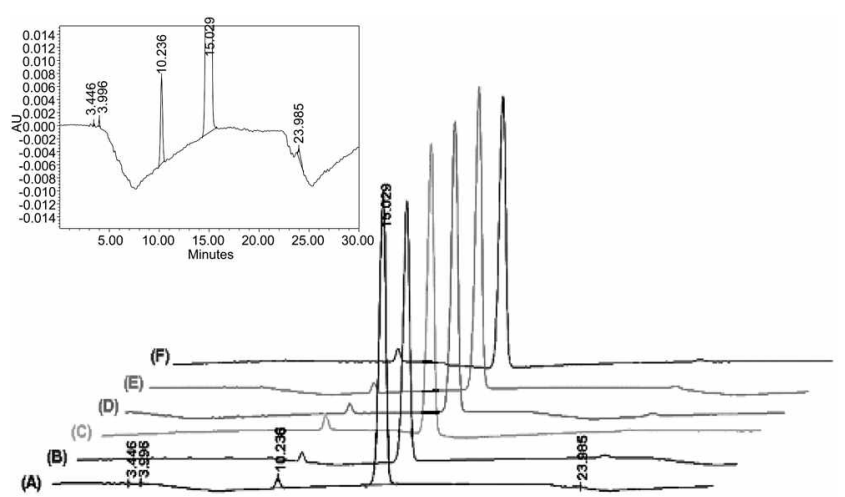

Figure 2. Chromatograms of six cetradine bulk diug samples $(A \sim F)$ and an enlarged chromatogram of sample $A$ for the anal sis of inpurities in cefradine according to the "cefalexin method" prescribed by the EP.

HPLC results for retention time and \% area for each of the six peaks corresponding to the six ( $\mathrm{Sa} A \sim \mathrm{F}$ ) bulk drugs are summarized in Table 4 and representative chromatograms for each bulk drug are shown in Figure 2. The results of HPLC analysis summarized in Table 4 clearly demonstrate the ratio of cefradine cefalexin and three or four unknown impurities. although the chromatograph baselines were somewhat unstable.

According to EP specifications. the content of cefradine. when used as an active ingredient. should be not less than $90.0 \%$. In addition. the content of cefalexin as a major impurity should be not more than $5.0 \%$, while the content of any other extraneous impurities should not exceed $1.0 \%$. Therefore. it was concluded that the cefradine bulk drugs. A. B. D. E and F, did not meet EP specifications. because the content of three or four unknown impurities was greater than $1.0 \%$ as shown in Table 4 .

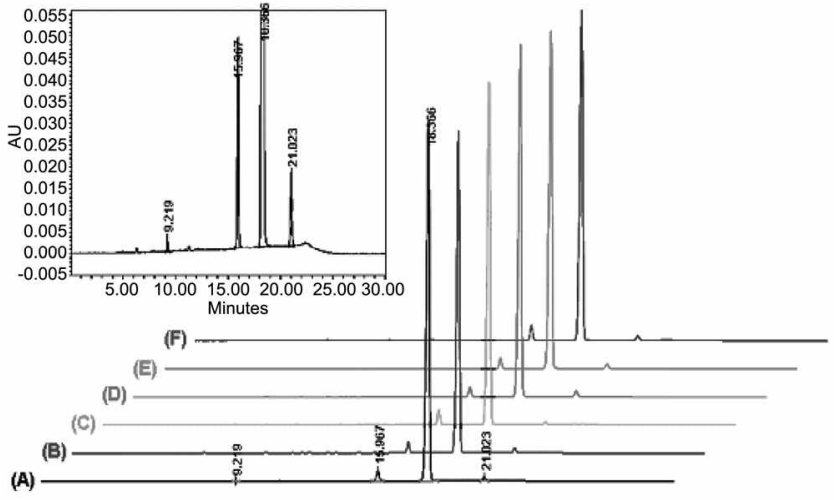

Figure 3. Chromatograms of six cetradine bulk drug samples $(A \sim F)$ and an enlarged chromatogram of sample $A$ for the analysis of impurities in cefradine according to the "cefadroxil method" prescribed by the EP.

Chromatographic results for determination of impurities in cefradine with "cefadroxil method".

Determination of impurities in cefradine: As shown in Figure 1. the structure of cefradine is similar to that of cefadroxil. Consequently. the chromatographic conditions described for the "cefadroxil method" except for the UV detection wavelength can be applied to the determination of impurities in cefradine. The UV detection wavelength for cefradine was set to $254 \mathrm{~nm}$. as shown in Table 3 while the wavelength used for cefadroxil was $220 \mathrm{~nm}$. according to the "cefadroxil method".

Representative chromatograms for the six cefradine (Sa A F) bulk drugs are shown in Figure 3. The baselines of the chromatograns shown in Figure 3 were much more stable than those obtained with the "cefalexin method" shown in Figure 2. Retention time and \% area for each of the six cefradine $(\mathrm{Sa} A \sim \mathrm{F})$ bulk drugs are summarized in Table 5. 
Table 5. Chromatographic results including retention time and \% area of each peak obtained with the "cefadroxil method" for six cefradine bulk drug samples $(A \sim F)$

\begin{tabular}{|c|c|c|c|c|c|c|c|}
\hline $\mathrm{Sa}$ & RT & $\%$ Area $^{2}$ & Compound & $\mathrm{Sa}$ & RT & $\%$ Area & Compound \\
\hline \multirow{4}{*}{ A } & 9.18 & 0.13 & $\mathrm{UN}^{b}$ & \multirow{5}{*}{ D } & 9.21 & 0.09 & UN \\
\hline & 15.94 & 2.48 & Cefalexin & & 11.28 & 0.13 & UN \\
\hline & 18.34 & 96.42 & Cetradine & & 15.95 & 2.11 & Cetalexin \\
\hline & 20.99 & 0.97 & UN & & 18.35 & 96.20 & Cefradine \\
\hline \multirow{6}{*}{ B } & 6.27 & 0.11 & UN & & 21.00 & 1.46 & $\mathrm{UN}$ \\
\hline & 9.20 & 0.21 & UN & \multirow{5}{*}{$\mathrm{E}$} & 11.27 & 0.09 & UN \\
\hline & 11.26 & 0.15 & UN & & 15.94 & 249 & Cetalexin \\
\hline & 15.95 & 2.82 & Cefalesin & & $\begin{array}{l}15.94 \\
18.34\end{array}$ & $\begin{array}{r}2.49 \\
96.27\end{array}$ & Cefradine \\
\hline & 18.33 & 95.26 & Cetradine & & $\begin{array}{l}10.34 \\
21.00\end{array}$ & 1.14 & UN \\
\hline & 21.00 & 1.45 & UN & & & & \\
\hline \multirow{7}{*}{$\mathrm{C}$} & 6.26 & 0.15 & UN & \multirow{7}{*}{ F } & 6.26 & 0.13 & UN \\
\hline & 9.20 & 0.10 & UN & & 9.19 & 0.14 & UN \\
\hline & 15.94 & 3.61 & Cefalexin & & 11.27 & 0.21 & UN \\
\hline & 18.33 & 95.10 & Cetradine & & 1595 & 3.68 & Cetalexin \\
\hline & 21.00 & 0.69 & UN & & 1833 & 9467 & Cefradine \\
\hline & 22.37 & 0.17 & UN & & $\begin{array}{l}18.33 \\
21.00\end{array}$ & $\begin{array}{r}94.07 \\
1.17\end{array}$ & $\begin{array}{l}\text { UNIIdone } \\
\text { IN }\end{array}$ \\
\hline & 22.77 & 0.18 & UN & & $21, \pi$ & 1.17 & \\
\hline
\end{tabular}

"Arerage of ${ }^{\circ} \cdot 0$ Area to 3 times. "Vnkinown

Table 6. Comparison of the "cefalexin" and "cefadroxil" methods regarding \% area and \% RSD of the major ingredient, cefradine, in six cefradine bulk drugs $(A \sim F)$

\begin{tabular}{rlrrrrrrr}
\hline \multicolumn{2}{c}{ Sample } & A & B & C & D & E & \multicolumn{1}{c}{ F } \\
\hline \multirow{2}{*}{ Cetalexin method } & Mean \%area & 96.63 & 96.20 & 95.65 & 96.14 & 96.61 & 95.47 \\
& \%RSD & 0.20 & 0.14 & 0.11 & 0.17 & 0.03 & 0.05 \\
\hline \multirow{2}{*}{ Cefadroxil method } & Mean \%area & 96.42 & 95.26 & 95.10 & 96.20 & 96.27 & 94.67 \\
& \%RSD & 0.02 & 0.08 & 0.05 & 0.06 & 0.04 & 0.06 \\
\hline
\end{tabular}

Table 7. Comparison of the "cefalexin" and "cefadroxil" methods regarding \% area and \% RSD of the major impurity, cefalexin, in six cefradine bulk $\operatorname{drugs}(\mathrm{A} \sim \mathrm{F})$

\begin{tabular}{llllllll}
\hline \multicolumn{2}{c}{ Sample } & A & B & C & D & E & F \\
\hline \multirow{2}{*}{ Cefalexin method } & Mear \%area & 2.34 & 214 & 346 & 2.26 & 226 & 327 \\
& \%RSD & 0.03 & 0.12 & 0.04 & 0.08 & 0.10 & 0.02 \\
\hline \multirow{2}{*}{ Cefadroxil method } & Mean \%area & 2.48 & 2.82 & 361 & 2.11 & 2.49 & 368 \\
& \%RSD & 0.02 & 0.04 & 0.03 & 0.05 & 0.04 & 0.04 \\
\hline
\end{tabular}

The retention times of cefalexin and cefradine were approximately 16 and $18 \mathrm{~min}$. respectively, with good reproducibility. The cefalexin content in each of the six cefradine bulk drugs tested was less than $5.0 \%$ and was within EP specifications.

According to EP specifications, the content of any extraneous impurity in cefradine must be less than $1.0 \%$ (Table 2). However. the impurity content observed at $21 \mathrm{~min}$ was greater than $1.0 \%$ for cefradine bulk drugs B. D. E and F. In addition. the total extraneous impurity content was more than $1.0 \%$ for all six cefradine bulk drugs. In this instance. none of the six cefradine bulk dnugs tested. A. B. C. D. E and F. were deemed appropriate for use as drugs.

Comparison of the "cefalexin" and "cefadroxil" methods for the assay of cefradine bulk drugs. The precision of the two HPLC methods for determination of cefradine. cefalexin and any other detectable impurities in cefradine bulk drugs was compared. The \% area and \% RSD observed with the two methods for cefradine content in six cefradine bulk drugs are summarized in Table 6 . The $\%$ RSDs for the $\%$ areas observed with the "cefadroxil method" (0.02-0.08) were superior to those obtained with the "cefalexin method" (0.05-0.20). The \% area and \% RSD for the cefalexin content in six cefradine bulk drugs are also summarized in Table 7. As shown in Table 7. the \% RSDs for the \% areas obtained using the "cefadroxil method" (0.02-0.05) were also superior to those obtained with the "cefalexin method" (0.0-20.12). From the extended chromatograms shown in Figures 2 and 3 , it is evident that the stability of the chromatograph baseline was greater with the "cefadroxil method" than with the "cefalexin method." Overall. the "cefadroxil method" is concluded to be quite reliable in determining cefalexin, the major impurity in cefradine and any other extraneous impurities in cefradine bulk drugs. 


\section{Conclusions}

In this study, two different HPLC methods were evaluated in their performance for determination of impurities in cefradine bulk drugs. Even though TLC method is prescribed as the official method for determination of extraneous impurities in cefradine by the EP. HPLC method is superior to TLC method in terms of simple sample preparation. greater sensitivity and reproducibility. Between the two HPLC methods. the "cefadroxil method" was found to be superior to the "cefalexin method" due to greater baseline stability and precision. The "cefadroxil method" would be a suitable replacement for TLC method as the official method for determination of impurities in cefradine. In our future study. the "cefadroxil method" will be extended to the quantitative analysis of cefaclor and amoxicillin. which are similar to cefadroxil in their structures.

Acknowledgements. This work was supported by KBSI grant (N28086) to J. S. Jin and MOCIE-RTI04-02-01.

\section{References}

1. Emaldi. P.: Fapanui, S.; Baldini, A. J. Chomatogr: A 1995. 711, 339.

2. Yongxin, Z: Hendrix C: Busson. R: Janssen. G: Roets, E: Hoogmartens. J. J. Pharm Bioned Anal 1994, 12, 1137.

3. Hendrix. C.: Yongxin. Z.: Pijcke. M.: Roets. E.: Hoogmartens. J. J. Pham Bionted Anal 1993. H. 595.

4. Crombez. E: Bens. G. A.: Van der Weken. G.: Van den Bossche. W: De Moerloose, P. Clromatographia 1978, 11.653.

5. White, E: Roderick J: Zarembo. E. J. Amtibiotics 1981, 34, 836.
6. Moore. C. M.: Sato. K.: Katsumata. Y. J. Chrontatogr: B 1991. 539.215.

7. Morsch. L. M.: Bittencoutt. I.: Souza. M. J. Pharnt. Bionted. And. 2002, 30.643.

8. Yun, E. K.: Prince. A. J:- McMillin. J. E.; Welch, E. J. Chromatog: $B$ 1998. 712.145

9. Farag. S. A. J.AOAC Im. 1998. 81.381

10. Ting. S. J. Assoc Off Anal. Chem. 1998. 71. 1123.

11. Nishino. I.: Fujitomo. H.: Unneda. T. J. Chromatogr: $B$ 2000. $7+9$. 101 .

12. Bafeltowski, J. J.: Buszman, E.: Mandat. K.: Hawranek, J. d. Chromatogr: A 2002. 976, 249.

13. Gallo Martinez. L.: Campins Falco. P.: Sevillano. A.: Caleza. A. J. Phom Bioned dinal 2012. 29.405.

14. Johnson. V. M.: Allanson. J. P.: Causon. R. C. J. Chromatogr: $B$ 2000. 740,71

15. Guitton, J; Laffont. A.: Rochet-Mingret, L; Bonnefoy, M: Bureau, J. J. Chromatogr: B 1998. 719.151.

16. Nee Ling. S. S.: Yuen. K. H.: Barker. S. A. J. Chontatogr. B 2003. 783.297.

17. Hanko. V. P.: LaCourse. W. R.: Dasenbrock. C. O.: Rohrer. J. S. Drug Development Research 2001, 53, 268.

18. Monograph Cefradine in European Phamacopoeia. $5^{\text {th }}$ ed.: Suppl. 5.0. European Directorate for Quality of Medicines: Strasbourg. France. 2005

19. Monograph Cephradine in Chited States Phamacopoeia Tational Fommlan; Linted State Pharnacopoeial Comention. $24^{\text {th }}$ ed.: United States Pharmacopoeia National Formulary: Rock wille. MD. 2000.

20. Mou. S.: Ding, X; Liu. Y. J. Chromatogr: B 2002. 781, 251

21. Ahuja. S. S. Adronced Dng Detnery Review's 2007. 59.3.

22. Nageswara Rao. R.: Nagaraju. V. J. Pharnt. Bioned. Anol 2003. 33.335.

23. Monograph Cefadroxil Honolndrate in Ewopean Phannacopoeia, $5^{\text {th }}$ ed.; Suppl. 5.0. European Directorate for Quality of Medicines: Strasbourg. France, 2005. 